\title{
Evaluation of Gluten-Free Diet Efficacy for Improving Quality of Life of Patients with Celiac Disease
}

\author{
Pezhman Alavinejad (iD ${ }^{1,{ }^{*}}$, Yosra Shafiolleh Talokdar ${ }^{1}$ and Zahra Shokati Ashkiki ${ }^{1}$ \\ ${ }^{1}$ Alimentary Tract Research Center, Ahvaz Jundishapur University of Medical Sciences, Ahvaz, Iran \\ "Corresponding author: Alimentary Tract Research Center, Ahvaz Jundishapur University of Medical Sciences, Ahvaz, Iran. Email: pezhmanalavinejad@gmail.com
}

Received 2020 August 06; Revised 2020 October 31; Accepted 2020 November 03.

\begin{abstract}
Background: As the only effective treatment of celiac disease (CD) is a lifelong commitment to a gluten-free diet (GFD), this study was designed to evaluate the efficacy of GFD in the quality of life (QOL) of patients with CD to persuade them for strict commitment. Methods: In a cross-sectional study, the QOL of CD patients registered in the celiac society of Khuzestan province was evaluated and compared before and at least one year after commencing GFD using the QOL SF-36 questionnaire.

Results: Overall, $200 \mathrm{CD}$ patients ( 66 males and 134 females) were evaluated. The average age of male and female participants was 26.3 and 30.34 years, respectively (61\% between 20 and 60-years-old). After GFD, complaints such as bloating $(\mathrm{P}=0.001)$, abdominal pain $(\mathrm{P}=0.001)$, diarrhea $(\mathrm{P}=0.001)$, nausea $(\mathrm{P}=0.001)$, vomiting $(\mathrm{P}=0.03)$, reflux and regurgitation $(\mathrm{P}=0.025)$, anorexia $(\mathrm{P}=$ $0.001)$, fatigue $(P=0.001)$, headache $(P=0.008)$, oral aphthous lesions $(P=0.014)$, weight loss $(P=0.001)$, and bone pain $(P=0.005)$ significantly improved while other symptoms such as muscular pain $(\mathrm{P}=0.157)$, dermatitis $(\mathrm{P}=0.083)$, and numbness $(\mathrm{P}=0.317)$ did not show any major improvement. The average scores of QOL before and after GFD were 0.74 and 3.41, respectively, which demonstrated significant improvement $(\mathrm{P}=0.001)$. This improvement was even seen among cases with sub-optimal compliance (average QOL score 3.28, $\mathrm{P}=0.001$ ).

Conclusion: A gluten-free diet could significantly improve the quality of life of patients with celiac disease, and they should be encouraged as much as possible to be committed to this regimen.
\end{abstract}

Keywords: Celiac Disease, Quality of Life (QOL), Gluten-Free Diet

\section{Background}

Celiac disease $(\mathrm{CD})$ is an immune system disorder that is clinically present among genetically susceptible subjects $(1,2)$. The soluble part of gluten, gliadin, plays a major role in the pathogenesis of this disorder and may result in villous atrophy and crypt hyperplasia (3). These mucosal alterations and immune reactions can result in a wide range of Gastrointestinal and/or other organ complications (4-6). The global prevalence of celiac disease is about 0.5 to $1.5 \%$, while epidemiologic investigations estimate that atypical or silent and undiagnosed cases are much more prevalent than typical ones, which probably increase the real prevalence up to $6 \%$ in some community populations (7-13).

Between 80 and $90 \%$ of celiac patients remain undiagnosed. Because of late diagnosis, these patients may develop various complications, including malabsorption, anemia, bone loss, infertility, depression, or even cancer (14-18). Despite the increasing prevalence of CD and potential complications of this disorder, the only effective treatment of this condition is a lifelong commitment to a gluten-free diet (GFD) (19-21). While an effective treatment of CD necessitates a lifelong commitment to GFD, this regimen is more expensive than a normal diet and carries a social liability (22-24).

\section{Objectives}

we should have strong evidence to persuade not only CD patients to be committed to GFD but also health care workers, advisory teams, and social services to have more effective participation and observance. In this regard, the current study evaluated the quality of life (QOL) of CD patients after commencing GFD in the Khuzestan province of Iran.

\section{Method}

In a cross-sectional study, we assessed the QOL of CD patients registered in the celiac society of Khuzestan province for more than one year before the study. The CD 
diagnosis was based on the subject's clinical history, histological appearance of the small intestinal mucosa, and their clinical responses to the withdrawal of gluten (25). The $\mathrm{CD}$ cases were evaluated and compared before and at least one year after commencing GFD by using the QOL SF36 questionnaire. During the routine clinical meeting or by phone calls, all of the participants were requested to fill a questionnaire while their personal information remained confidential. The $\mathrm{CD}$ patients were asked to rank their general health, as part of the SF-36 questionnaire, on a five-point scale compared to one year ago. For the quantitative estimate of the QOL parameters and calculation of a 'transformed score', formulae provided with the SF36 questionnaire. The Health Survey Questionnaire Short Form 36 (SF-36) was developed in the USA for use in the Rand Corporation's Health Insurance Experiment (26). The measure has been translated into 120 languages and used around the world to gauge the health of local populations (27-29).

The inclusion criterion included a history of $\mathrm{CD}$ for at least one year before the study as registered in the celiac society of Khuzestan province and the exclusion criterion was the patients' unwillingness or refusal to participate in the study. Subjects also signed a consent form before participation in the study. The rate of commitment to GFD was evaluated by comparing the serum level of $\mathrm{CD}$ serologic markers (anti-TTG, anti-EMA, and anti-gliadin antibodies) before and after GFD, and defined as optimal (serum level of zero or close to the lower limit of normal), sub-optimal (decreased serum level of anti-bodies but close to the upper limit of normal), and non-compliant (no decrease or even a raise in the titer). The study was approved by the Ethics Committee of Ahvaz Jundishapur University of Medical Sciences (IR.AJUMS.REC.1398.161).

The collected data were analyzed by SPSS version 19 using the test and the chi-square test. In all the tests, $\mathrm{P}<0.05$ was considered significant.

\section{Results}

Overall, $200 \mathrm{CD}$ patients (66 males and 134 females) were included. The average age of male and female participants was 26.3 and 30.34 years, respectively (61\% between 20 and 60-years-old). Based on the serum level of serologic markers, 146 (73\%) cases were defined as optimal GFD cases, and $54(27 \%)$ patients as suboptimal ones.

After at least one year since commencing GFD, complaints such as bloating $(\mathrm{P}=0.001)$, abdominal pain $(\mathrm{P}=$ $0.001)$, diarrhea $(P=0.001)$, nausea $(P=0.001)$, vomiting $(\mathrm{P}=0.03)$, reflux and regurgitation $(\mathrm{P}=0.025)$, anorexia $(P=0.001)$, fatigue $(P=0.001)$, headache $(P=0.008)$, oral aphthous lesions $(\mathrm{P}=0.014)$, weight loss $(\mathrm{P}=0.001)$, and bone pain $(P=0.005)$ significantly improved while other symptoms such as muscular pain $(\mathrm{P}=0.157)$, dermatitis $(\mathrm{P}$ $=0.083)$, and numbness $(P=0.317)$ did not show any major improvement (Table 1).

\begin{tabular}{lccc}
\hline Table 1. Patients' Symptoms Before and After Commencing a Gluten-Free Diet ${ }^{\mathrm{a}}$ \\
\hline Complain & Before GFD & After GFD & P value \\
\hline Bloating & $74(37)$ & $5(2.5)$ & 0.001 \\
\hline Abdominal pain & $43(21.5)$ & $2(1)$ & 0.001 \\
\hline Diarrhea & $27(13.5)$ & $0(0)$ & 0.001 \\
\hline Constipation & $10(5)$ & $0(0)$ & 0.001 \\
\hline Nausea & $14(7)$ & $0(0)$ & 0.001 \\
\hline Vomiting & $9(4.5)$ & $0(0)$ & 0.003 \\
\hline Regurgitation & $5(2.5)$ & $0(0)$ & 0.025 \\
\hline Anorexia & $21(10.5)$ & $0(0)$ & 0.001 \\
\hline Fatigue & $18(9)$ & $0(0)$ & 0.001 \\
\hline Headache & $7(3.5)$ & $0(0)$ & 0.008 \\
\hline Bone pain & $8(4)$ & $0(0)$ & 0.005 \\
\hline Oral aphthous lesion & $6(3)$ & $0(0)$ & 0.014 \\
\hline Weight loss & $15(7.5)$ & $0(0)$ & 0.001 \\
\hline Dermatitis & $4(2)$ & $1(0.5)$ & 0.083 \\
\hline
\end{tabular}

Abbreviation: GFD, gluten-free diet.

${ }^{\mathrm{a}}$ Values are expressed as No. (\%).

The average scores of QOL before and after GFD were 0.74 and 3.41, respectively, which demonstrated significant improvement $(\mathrm{P}=0.001)$ (Table 2). This improvement was even seen among cases with sub-optimal compliance (average QOL score 3.28, $\mathrm{P}=0.001$ ).

\section{Discussion}

In general, to quantify the degree of impairment in many chronic diseases like $C D$, we evaluate the quality of life parameters, but there are not enough studies that have assessed the gluten-free diet's role in the QOL of celiac patients detected by serological screening. Therefore, we examined the effect of GFD in CD patients who may ingest gluten. Despite having typical gluten-triggered lesions of the small-bowel mucosa, these patients have nonspecific, minor, or even specific symptoms. The study showed that the QOL parameters of screen-detected CD patients differed significantly before and after commencing GFD. Compared to similar studies, the number of $\mathrm{CD}$ patients in our study was good enough to detect a significant difference $(20,30,31)$.

After one year of using GFD, three of the SF-36 parameters did not significantly differ in our subjects, compared 


\begin{tabular}{|c|c|c|c|}
\hline Parameter & Average Score Before GFD & Average Score After GFD & P Value \\
\hline General health & 0.76 & 2.4 & 0.016 \\
\hline Limitations of activities & 0.76 & 4.2 & 0.001 \\
\hline Physical health problems & 0.59 & 3.6 & 0.003 \\
\hline Emotional health problems & 0.88 & 5.1 & 0.001 \\
\hline Social activities & 0.94 & 2.9 & 0.012 \\
\hline Energy and emotions & 0.67 & 2.6 & 0.024 \\
\hline Pain & 0.58 & 3.1 & 0.001 \\
\hline Average & 0.74 & 3.41 & 0.001 \\
\hline
\end{tabular}

Abbreviations: GFD, gluten-free diet; QOL, quality of life.

to the last year, but other parameters improved significantly. However, the value of using a strict lifelong GFD in cases that have minor or nonspecific symptoms is still unknown (31). Also, in such patients, symptoms may manifest clinically later in their life, with malabsorption signs (32). In some subjects, even with absent gastrointestinal symptoms, the symptoms may also occur with extra-intestinal complications (33-35). Thus, the early detection of celiac disease in these cases and their treatment may help improve such complications (36).

The QOL in treated celiac patients may be affected by different factors. According to a recent report, the burden of disease in CD women using GFD for several years was worse than that in men, despite similar QOL measures (37). Another study also described how CD patients with typical symptoms of Irritable Bowel Syndrome (IBS) often report impaired QOL in all parameters and fail to obtain an optimal subjective sense of well-being, despite improvements in some QOL parameters after GFD (38). Depression and anxiety are often prevalent in CD patients. As previously described, psychological general well-being and abdominal discomfort are highly personal and subjective matters that depend on the environment and personality (39). We used validated and standardized questionnaires to assess these common features, allowing us to assess the GFD role in the QOL of CD patients (40). One of our main findings was that after the introduction of GFD, most subjects reported improved psychological well-being, which is contrary to a recent report (41). Another important finding of this study was an impressive improvement in gastrointestinal symptom scores of the CD patients. These findings are in agreement with the Mustalahti et al. report (31).

Overall, our study suggested that the QOL of patients with CD improved after one year of GFD although we could not determine whether this improvement was permanent or not. In this regard, Hallert et al. reported that after over a 10-year follow-up, CD patients failed to achieve the same level of well-being as normal people (42). Thus, our observation about the QOL improvement in CD patients may only be temporary. In our study, the overall improvement in QOL was observed after one year of commencing GFD. The limitation of this study was its design as a retrospective one.

\subsection{Conclusion}

In conclusion, the $\mathrm{CD}$ is a chronic disease with a wide range of presentations that can affect different aspects of life and influence the QOL. Our findings suggest that at least one year of a gluten-free diet is useful and may improve the QOL of CD patients even among those with suboptimal compliance. Nonetheless, more studies are needed to prove the long-term benefits or even harms of CD patients' treatment with a gluten-free diet.

\section{Acknowledgments}

This article was extracted from a thesis by Dr. Yosra Shafiollah for her MD degree. This study was performed under the supervision of Khuzestan celiac society with no financial support.

\section{Footnotes}

Authors' Contribution: Pezhman Alavinejad was the corresponding author. Yosra Shafiolleh Talokdar was the data collector. Zahra Shokati Ashkiki wrote the article.

Conflict of Interests: None to declare.

Ethical Approval: The study was approved by the Ethics Committee of Ahvaz Jundishapur University of Medical Sciences (IR.AJUMS.REC.1398.161).

Funding/Support: This work was supported by the Alimentary Tract Research Center without a financial grant. 
Informed Consent: Subjects also signed a consent form before participation in the study.

\section{References}

1. Sollid LM, Jabri B. Is celiac disease an autoimmune disorder? Curr Opin Immunol.2005;17(6):595-600.doi:10.1016/j.coi.2005.09.015.[PubMed: 16214317].

2. Fasano A. Surprises from celiac disease. Sci Am. 2009;301(2):54-61. doi: 10.1038/scientificamerican0809-54. [PubMed: 19634568].

3. Shan L, Molberg O, Parrot I, Hausch F, Filiz F, Gray GM, et al. Structural basis for gluten intolerance in celiac sprue. Science. 2002;297(5590):2275-9. doi: 10.1126/science.1074129. [PubMed: 12351792].

4. Levy J, Bernstein L, Silber N. Celiac disease: an immune dysregulation syndrome. Curr Probl Pediatr Adolesc Health Care. 2014;44(11):324-7. doi: 10.1016/j.cppeds.2014.10.002. [PubMed: 25499458].

5. Melicharova J, Slavik M, Cervinkova M. Psychological aspects in celiac disease: Step by step from symptoms to daily life with celiac disease. Int J Celiac Dis. 2016;4(2):64-7.

6. Alavinejad P, Hajiani E, Masjedizadeh R, Hashemi SJ, Faramarzi M, Sebghatollahi V, et al. Epidemiologic and demographic survey of celiac disease in khuzestan province. MEJDD. 2014;6(2):98.

7. Ahadi Z, Shafiee G, Razmandeh R, Keshtkar AA, Najafi Sani M, Azemati $B$, et al. Prevalence of celiac disease among the Iranian population: A systematic review and meta-analysis of observational studies. Turk J Gastroenterol. 2016;27(2):122-8. doi: 10.5152/tjg.2015.150191. [PubMed: 27015617].

8. Mahmoodi A, Jafarihaydarlo A, Yasemi M, Hemati K, Peyman H. Celiac disease prevalence in the patients with irritable bowel syndrome in the ilam province; a cross sectional study from Western iran. $J$ Clin Diagn Res. 2014;8(12):GC01-3. doi: 10.7860/JCDR/2014/10175.5286. [PubMed: 25653962]. [PubMed Central: PMC4316268].

9. Singh P, Arora A, Strand TA, Leffler DA, Catassi C, Green PH, et al. Global prevalence of celiac disease: Systematic review and meta-analysis. Clin Gastroenterol Hepatol. 2018;16(6):823-836 e2. doi: 10.1016/j.cgh.2017.06.037. [PubMed: 29551598].

10. Lerner A, Jeremias $P$, Matthias T. The world incidence and prevalence of autoimmune diseases is increasing. Int J Celiac Dis. 2016;3(4):151-5. doi: 10.12691/ijcd-3-4-8.

11. Ramakrishna BS, Makharia GK, Chetri K, Dutta S, Mathur P, Ahuja $\mathrm{V}$, et al. Prevalence of adult celiac disease in india: Regional variations and associations. Am J Gastroenterol. 2016;111(1):115-23. doi: 10.1038/ajg.2015.398. [PubMed: 26729543].

12. West J, Logan RF, Hill PG, Khaw KT. The iceberg of celiac disease: what is below the waterline? Clin Gastroenterol Hepatol. 2007;5(1):59-62. doi: 10.1016/j.cgh.2006.10.020. [PubMed: 17234556].

13. Chen CY, Li JN. Insufficient awareness of celiac disease in China: population-based screening is needed. Chin Med J (Engl). 2019;132(13):1513-5. doi: 10.1097/CM9.0000000000000305. [PubMed: 31188159]. [PubMed Central: PMC6616242].

14. Jabeen R. Complications of Celiac Disease. Celiac Disease: From the Bench to the Clinic. IntechOpen; 2019. doi: 10.5772/intechopen.80465.

15. Saccone G, Berghella V, Sarno L, Maruotti GM, Cetin I, Greco L, et al. Celiac disease and obstetric complications: a systematic review and metaanalysis. Am J Obstet Gynecol. 2016;214(2):225-34. doi: 10.1016/j.ajog.2015.09.080. [PubMed: 26432464].

16. Choung RS, Larson SA, Khaleghi S, Rubio-Tapia A, Ovsyannikova IG, King KS, et al. Prevalence and morbidity of undiagnosed celiac disease from a community-based study. Gastroenterology. 2017;152(4):830-839 e5. doi: 10.1053/j.gastro.2016.11.043. [PubMed: 27916669]. [PubMed Central: PMC5337129].

17. Paez MA, Gramelspacher AM, Sinacore J, Winterfield L, Venu M. Delay in diagnosis of celiac disease in patients without gas- trointestinal complaints. Am J Med. 2017;130(11):1318-23. doi 10.1016/j.amjmed.2017.05.027. [PubMed: 28623177].

18. Malamut G, Cellier C. Complications of coeliac disease. Best Pract Res Clin Gastroenterol. 2015;29(3):451-8. doi:10.1016/j.bpg.2015.05.005. [PubMed: 26060109].

19. Armstrong C. ACG releases guideline on diagnosis and management of celiac disease. Am Fam Physician. 2014;89(6):485-7. [PubMed: 24695571].

20. Pinto-Sanchez MI, Bai JC. Toward new paradigms in the follow up of adult patients with celiac disease on a gluten-free diet. Front Nutr. 2019;6:153. doi:10.3389/fnut.2019.00153. [PubMed:31632977].[PubMed Central: PMC6781794].

21. Akobeng AK, Thomas AG. Systematic review: tolerable amount of gluten for people with coeliac disease. Aliment Pharmacol Ther 2008;27(11):1044-52. doi: 10.1111/j.1365-2036.2008.03669.x. [PubMed: 18315587].

22. Singh J, Whelan K. Limited availability and higher cost of glutenfree foods. J Hum Nutr Diet. 2011;24(5):479-86. doi: 10.1111/j.1365 277X.2011.01160.x. [PubMed: 21605198].

23. Burden M, Mooney PD, Blanshard RJ, White WL, Cambray-Deakin DR, Sanders DS. Cost and availability of gluten-free food in the UK: in store and online. Postgrad Med J. 2015;91(1081):622-6. doi 10.1136/postgradmedj-2015-133395. [PubMed: 26310267].

24. Stevens L, Rashid M. Gluten-free and regular foods: a cost comparison. Can J Diet Pract Res. 2008;69(3):147-50. doi: 10.3148/69.3.2008.147. [PubMed: 18783640].

25. Walker-Smith J. Revised criteria for diagnosis of coeliac disease Report of Working Group of European Society of Paediatric Gastroenterology and Nutrition. Arch Dis Child. 1990;65(8):909-11. doi: 10.1136/adc.65.8.909. [PubMed: 2205160]. [PubMed Central: PMC1792502].

26. Ware JE, Davies AR, Donald CA. Conceptualization and measurement of health for adults in the health insurance study: Vol. V, general health perceptions. Rand Corporation; 1978.

27. Garratt AM, Ruta DA, Abdalla MI, Buckingham JK, Russell IT. The SF36 health survey questionnaire: an outcome measure suitable for routine use within the NHS? BMJ. 1993;306(6890):1440-4. doi: 10.1136/bmj.306.6890.1440. [PubMed: 8518640]. [PubMed Central: PMC1677883].

28. Ware JE, Snow KK, Kosinski M, Gandek BS. SF-36 health survey manual and interpretation guide. New England Medical Center, the Health Institute, Boston. 1993.

29. Bowling A, Bond M, Jenkinson C, Lamping DL. Short Form 36 (SF36) Health Survey questionnaire: which normative data should be used? Comparisons between the norms provided by the Omnibus Survey in Britain, the Health Survey for England and the Oxford Healthy Life Survey. J Public Health Med. 1999;21(3):255-70. doi: 10.1093/pubmed/21.3.255. [PubMed: 10528952].

30. Peräaho M, Kaukinen K, Mustalahti K, Vuolteenaho N, Mäki M, Laip pala $\mathrm{P}$, et al. Effect of an oats-containing gluten-free diet on symptoms and quality of life in coeliac disease. A randomized study. Scand J Gastroenterol. 2004;39(1):27-31. doi: 10.1080/00365520310007783. [PubMed: 14992558].

31. Mustalahti K, Lohiniemi S, Collin P, Vuolteenaho N, Laippala P, Maki M. Gluten-free diet and quality of life in patients with screen-detected celiac disease. EffClin Pract. 2002;5(3):105-13. [PubMed: 12088289].

32. Maki M, Collin P. Coeliac disease. Lancet. 1997;349(9067):1755-9. doi: 10.1016/S0140-6736(96)70237-4. [PubMed: 9193393].

33. Cellier C, Flobert C, Cormier C, Roux C, Schmitz J. Severe osteopenia in symptom-free adults with a childhood diagnosis of coeliac disease. Lancet. 2000;355(9206):806. doi: 10.1016/S0140-6736(99)048552. [PubMed: 10711931].

34. Ciacci C, De Rosa A, de Michele G, Savino G, Squillante A, Iovino P, et al. Sexual behaviour in untreated and treated coeliac patients. Eur J Gastroenterol Hepatol. 1998;10(8):649-51. [PubMed: 9744692]. 
35. Pellecchia MT, Scala R, Perretti A, De Michele G, Santoro L, Filla A, et al. Cerebellar ataxia associated with subclinical celiac disease responding to gluten-free diet. Neurology.1999;53(7):1606-8. doi: 10.1212/wnl.53.7.1606-a. [PubMed:10534283].

36. Saari A, Harju S, Makitie O, Saha MT, Dunkel L, Sankilampi U. Systematic growth monitoring for the early detection of celiac disease in children. JAMA Pediatr. 2015;169(3). e1525. doi: 10.1001/jamapediatrics.2015.25. [PubMed: 25730696].

37. Hallert C, Granno C, Hulten S, Midhagen G, Strom M, Svensson $\mathrm{H}$, et al. Living with coeliac disease: controlled study of the burden of illness. Scand J Gastroenterol. 2002;37(1):39-42. doi: 10.1080/003655202753387338. [PubMed: 11843033].

38. O'Leary C, Wieneke P, Buckley S, O'Regan P, Cronin CC, Quigley EM, et al. Celiac disease and irritable bowel-type symptoms. Am J Gastroenterol. 2002;97(6):1463-7. doi: 10.1111/j.1572-0241.2002.05690.x. [PubMed: 12094866].
39. Dimenäs ES, Dahlöf CG, Jern SC, Wiklund IK. Defining quality of life in medicine. Scand J Prim Health Care.1990;1:7-10.

40. Dimenas E, Glise H, Hallerback B, Hernqvist H, Svedlund J, Wiklund I. Quality of life in patients with upper gastrointestinal symptoms. An improved evaluation of treatment regimens? Scand J Gastroenterol. 1993;28(8):681-7. doi: 10.3109/00365529309098272. [PubMed: 8210982].

41. Addolorato G, Capristo E, Ghittoni G, Valeri C, Masciana R, Ancona C, et al. Anxiety but not depression decreases in coeliac patients after one-year gluten-free diet: a longitudinal study. Scand J Gastroenterol. 2001;36(5):502-6. doi: 10.1080/00365520119754. [PubMed: 11346203].

42. Hallert C, Granno C, Grant C, Hulten S, Midhagen G, Strom M, et al. Quality of life of adult coeliac patients treated for 10 years. Scand J Gastroenterol. 1998;33(9):933-8. doi: 10.1080/003655298750026949. [PubMed: 9759948]. 